\title{
GREEN PHARMACY - A NARRATIVE REVIEW
}

\author{
ALEXANDRA TOMA, OFELIA CRIŞAN
}

\author{
Department of Pharmaceutical Legislation and Management, Iuliu Hatieganu \\ University of Medicine and Pharmacy, Cluj-Napoca, Romania
}

\begin{abstract}
Introduction. Active pharmaceutical ingredients are present in various sections of the environment, because of both the human and veterinary use of medicinal products. Ways of minimizing the risk of environmental contamination should be observed during all pharmaceutical activities (research, manufacturing, prescribing, dispensing and disposal of medicinal products).

Methods. For the present study we searched specific literature on this subject, using the main international databases (Thomson Reuters - Web of Science, SCOPUS and Science Direct).

Results. This narrative review focuses on the main aspects concerning environmental contamination with medicinal products. Consequently, the present study is structured on four different topics: environmental research on medicinal products, minimizing environmental contamination, waste disposal management and towards a greener community pharmacy.

Conclusion. Waste management activities are important for reducing the presence of active pharmaceutical ingredients in the environment. Pharmacists should inform patients on proper pharmaceutical waste disposal and organize collection programs for unused and expired medicines, in order to develop a greener pharmacy for the future.
\end{abstract}

Keywords: medicinal products, environment, pharmaceutical waste disposal, green pharmacy, active pharmaceutical ingredients

\section{Introduction}

Pollution represents one of the major problems that mankind faces nowadays. Pharmaceutical products (mainly medicinal products, but also other personal care products) may be regarded as environmental contaminants because of their worldwide use in both human and veterinary medicine [1-4]. Approximately more than 100,000 tons of medicinal products are consumed every year by human patients, the European Union (EU) market being the second biggest consumer in the world after the United States of America (USA) [5,6]. Moreover, 559 active pharmaceutical ingredients are found in environmental sectors such as surface water, groundwater, soil etc. [3]. In this context, a new concept has appeared, namely the green pharmacy concept, which can be defined as the sum of all measures that should be taken in order to minimize the

Manuscript received: 14.06.2018

Received in revised form: 31.07 .2018

Accepted: 11.09.2018

Address for correspondence: alexandra85.toma@gmail.com environmental impact of pharmaceuticals. Such measures should be applied during all pharmaceutical activities, from designing new molecules to manufacturing, distribution, dispensing and disposal [1,2,7-9]. Furthermore, healthcare professionals (physicians and pharmacists) and the final consumers (patients) should get involved in actions leading to pollution prevention caused by pharmaceutical products $[2,10]$. Pharmacists are responsible not only for dispensing prescription and over-the-counter (OTC) medicinal products, but also for proper pharmaceutical waste disposal, mostly derived from expired medicines $[1,10]$. Based on this consideration, two working groups of the International Pharmaceutical Federation (FIP), namely the Board of Pharmacy Practice and the Board of Pharmaceutical Science designed a document called "Green Pharmacy Practice: taking responsibility for the environmental impact of medicines" in order to provide guidelines for pharmacists in different practice settings [3]. The purpose of the paper is to provide a synthesized 
overview of the state of knowledge in the field of green pharmacy. The objectives are to summarize and analyze the relevant literature on preventing environmental contamination with pharmaceuticals. Our hypothesis is that pharmacists could be more involved in this field and we aim to develop future research directions for its regulation and implementation in Romania.

\section{Methods}

In order to write the current paper, we searched Thomson Reuters - Web of Science, SCOPUS and Science Direct, employing three different keywords: "green pharmacy", "pharmaceutical waste disposal" and "pharmaceuticals in the environment". A number of 230 articles were found, out of which 46 were related to phytotherapy and 64 were related to detection methodology and were therefore excluded from the start. From the remaining 120 articles, only 73 are cited in this review, as the most current, relevant and essential for our research. The results of this research were grouped in four areas, as follows.

\section{Environmental research on medicines}

The EU health policy defines medicinal products for human or veterinary use as "any substance or combination of substances presented as having properties for treating or preventing disease" or "any substance or combination of substances which may be used in or administered either with a view to restoring, correcting or modifying physiological functions by exerting a pharmacological, immunological or metabolic action, or to making a medical diagnosis" [11,12]. Such substances, often called active pharmaceutical ingredients or pharmaceutical active compounds may include any matter: human, animal, vegetable or chemical $[8,11-16]$. There are approximately 3000 active pharmaceutical ingredients authorized on the EU market, the medicinal products for human use ranging between 50 and $150 \mathrm{~g} /$ capita/year [6]. The consumption of medicinal products is one of the main sources of environmental contamination through excretion (urine, faeces) and inappropriate disposal of unused or expired medicines (toilet, sink, litter), as shown in figure 1 $[1,6,8,14]$.

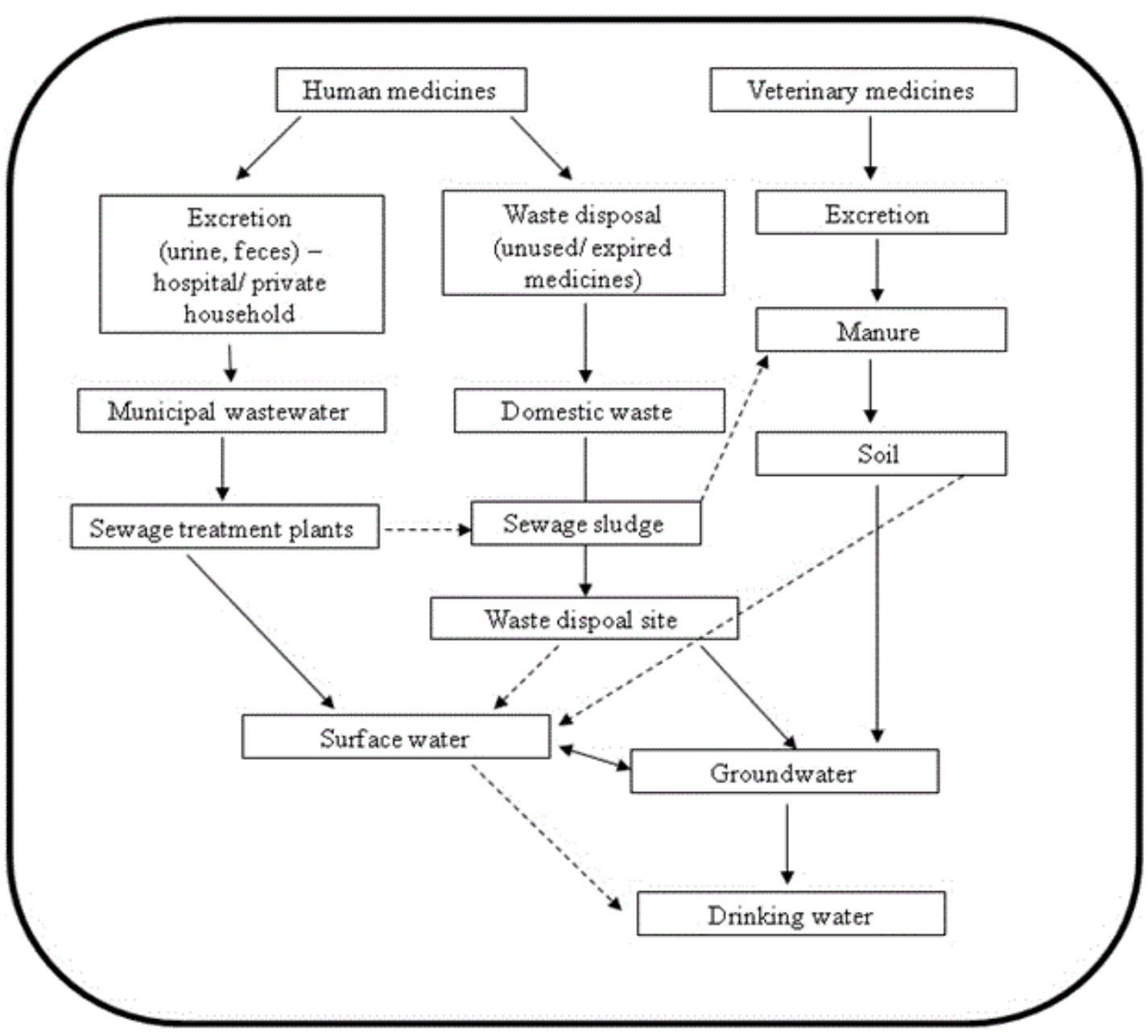

Figure 1. Diagram showing how medicinal products enter the environment [6]. 
Therefore, researchers conducted studies on the environment (soil and water samples) with the aim of discovering whether active pharmaceutical ingredients are present or not [14-22]. Most of the times, these molecules are found unchanged (parent compound) but they can also occur as active metabolites $[1,14]$. The concentration of active pharmaceutical ingredients in the environment (water) can range from ng/l up to $\mu \mathrm{g} / \mathrm{l}$ or even $\mathrm{mg} / \mathrm{l}$ (mostly in wastewaters) [3,23]. Another problem emphasized by many researchers is the accumulation of active pharmaceutical ingredients in the environment, which leads to continuous exposure and is more likely to produce negative effects on flora, fauna or even humans $[1,8,15,16,22-25]$. Such negative effects have already been reported in literature, for example: reproductive system disorders in fish caused by estrogens, the emergence of resistant bacteria caused by antibiotics or the death of some vulture species caused by diclofenac $[8,15,16]$.

Environmental studies showed the presence of various classes of medicinal substances in the aquatic system (groundwater, surface water and even drinking water) or in soil, such as:

a. antibiotics: macrolides (clarithromycin, erythromycin, roxithromycin, lincomycin), sulfonamides (sulfamethoxazole, trimethoprim, sulfadimethoxine, sulfamethazine, sulfathiazole), fluoroquinolones (ciprofloxacin, norfloxacin), chloramphenicol, tetracycline $\quad[14,15,17,22-24,26-28,30,31,35-40,43-$ 45,47,49,51,52,54,55-57];

b. antifungal substances: miconazole, fluconazole $[28,44,46]$;

c. antiviral substances: acyclovir, penciclovir, lamivudine, oseltamivir [44,51];

d. anti-inflammatory/ analgesic / antipyretic substances: diclofenac, ibuprofen, naproxen, ketoprofen, phenazone, salicylic acid (activemetabolite of acetylsalicylic acid), paracetamol $[14,15,19,22,23,27,28,30,31,33-45,47$ 52,54,56-58];

e. antiepileptic substances: carbamazepine, primidone [14-16,18,22,31,35-40,42-44,47,49-52,54-56];

f. antidepressants: fluoxetine, olanzapine, paroxetine etc $[15,18,28,29,32,44,52,54]$;

g. beta-blockers: metoprolol, propranolol, betaxolol, bisoprolol, nadolol, atenolol [14,22,30,31,33,35,36,43,44,4 $5,47,49,51,52,55]$;

h. diuretic substances: furosemide, hydrochlorothiazide $[33,35,36,43,49,52,56]$;

i. angiotensin converting enzyme inhibitors: enalapril, captopril [43];

j. anticoagulant substances: warfarin [44];

k. blood lipid regulators: bezafibrate, clofibric acid (active metabolite of clofibrate), gemfibrozil, fenofibric acid (active metabolite of fenofibrate), simvastatin $[14,22,23,27,28,30,31,33,40,43,47-49,54,56]$;

l.oralcontraceptives: estrogens(17 $\alpha$-ethinylestradiol, mestranol) [8,14,20,22,52,57];

m. cytostatic substances $[14,37]$;

n. antiemetic substances: domperidone [46];

o.contrast media [14];

p. antidiabetic substances: metformin, glibenclamide [14,20,22,35,36,44,51]; [28];

q. proton pump inhibitor substances: omeprazole

r. histamine $\mathrm{H} 2$ receptor antagonist substances: cimetidine, famotidine [44,51];

s. bronchodilator medicines [14,22,32];

t. sympathomimetic substances: ephedrine, pseudoephedrine [53];

u. narcotics and psychotropic substances: morphine, codeine, methadone, cocaine, 6-acetylmorphine, amphetamine, methamphetamine, 11-nor-9-carboxy$\Delta$-9-tetrahydrocannabinol, bromazepam, diazepam, lorazepam, lormetazepam, pentobarbital etc. $[8,14,15,18,22,29,32,35,36,42,47,50-52,56]$.

The occurrence of all the above-mentioned active pharmaceutical ingredients was detected in Germany, Austria, Italy, Spain, Greece, Croatia, Denmark, United Kingdom, Nederland, Switzerland, China, Brazil, the USA, Canada, Mexico, South Africa, Iraq, Saudi Arabia, India, Belgium, France, Portugal, Poland and Romania [1424,26-58].

\section{Minimizing environmental contamination}

Pharmaceutical activities include research, manufacturing, prescribing, dispensing and disposal of medicinal products. All these activities should be matched by actions in order to minimize the risk of environmental contamination with active pharmaceutical ingredients.

\section{Research and manufacturing medicinal products}

The pharmaceutical industry is involved in designing and manufacturing medicinal products. Most of the time, designing new bioactive compounds involves chemical synthesis, a process which increases the risk of environmental pollution due to the use of various organic and inorganic solvents. In order to minimize this negative impact on the environment, in the past few years researchers have developed the concept of "green chemistry", which can be described as being eco-friendlier. For example, the use of aqueous synthesis, solventfree synthesis and enzymes represent different "green chemistry" methods. Biotechnology is another way of ecodesigning new medicinal products $[1,2,8,9,59,60]$. During pharmaceutical research, a large number of molecules is usually obtained before an actual medicinal product can be tested and authorized. A method that can reduce the number of synthesized molecules is the evaluation of quantitative structure-activity relationship, which establishes the connection between the structure and the biological properties of newly designed molecules even before they are obtained [8]. 
Another challenge for the pharmaceutical industry is the manufacturing of medicinal products that can easily undergo biodegradation as soon as they reach the environment, mainly water and soil. Current medicinal products are metabolized through a series of reactions occurring in the liver, such as phase I reactions (catalyzed by Cytochrome P450) and phase II reactions. This transformation leads to the excretion of more hydrophilic metabolites, although it can also lead to the formation of the active compound in the case of the pro-drugs. In addition, the pharmaceutical industry needs to design technologies for manufacturing a "greener pill" that can have a therapeutic effect in the right dose at the right place and can still be eco-friendly. Such technologies include cocrystallization for improving bioavailability, salt formation, cyclodextrin encapsulation or obtaining amorphous forms for improved solubility [9,61]. Valproic acid is an example of medicinal product currently in use that can undergo rapid biodegradation through photodegradability during wastewater treatment [62]. Another example is carbamazepine that can suffer biodegradation using microorganisms (Streptomyces sp.) as bioremediation agents [63].

In order to obtain the marketing authorization for new medicinal products, manufacturers need to provide the environmental risk assessments if the expected environmental concentration of the active pharmaceutical ingredient in water is equal or higher than $1 \mu \mathrm{g} / \mathrm{l}$ according to the U.S. Food and Drug Administration or $0.01 \mu \mathrm{g} / 1$ according to the European Medicines Agency [1,5].

\section{Prescribing medicinal products}

As healthcare professionals, physicians are also responsible for prescribing medicinal products. In order to minimize the environmental impact of pharmaceuticals, prescribing should be rational, optimal and efficacious; otherwise it increases the consumption and accumulation of unused medicinal products [1,2]. According to the literature, various factors can influence both the consumption and the accumulation mentioned above. These include the patients' expectations and requests (for example antibiotics, often prescribed when their use is not needed, like for the common cold), over-prescribing, changes in medication therapy, prescribing medicinal products for treating side effects or for "use as needed", offering excessive free samples, unnecessary prescribing leading to medicine abuse, in-hospital prescribing of medicines that patients already have etc $[1,2,64]$.

One way of reducing both the side and the environmental effects of prescription medicinal products is by lowering normal doses. Some researchers showed that, most of the time, the therapeutic effect can be reached at smaller doses than the ones established by the manufacturer [1]. For example, the co-administration of naltrexone and morphine can produce an analgesic effect at lower doses of morphine thus reducing the risk of tolerance and dependence [65].

Individualized medicinal therapy can help prescribers tailor medicinal products for each patient $[1,66,67,68]$. Since genetic factors may influence the outcome of medicinal therapy, they provide an important framework for personalized medicine. Pharmacogenomics represents a new field in personalized medicine that can support physicians in prescribing a more efficient, safer and rational medicinal therapy $[2,67]$.

Physicians should also focus on reducing polytherapy, recommending lifestyle measures (diet, exercises etc.), empowering patients, verifying the pharmacokinetic profiles of medicines in order to select the ones that are easily and highly metabolized, etc [2].

\section{Dispensing and disposal of medicinal products}

According to some studies, factors relating to the dispensing of medicinal products may increase environmental contamination caused by pharmaceutical active compounds. Free or low-cost medicines may lead to the over accumulation of unused medicines. Sale at a distance to the public often leads to lost or damaged shipments. Consequently, some medicines cannot be used while some, including fake or counterfeit ones may become too freely available. Inaccurate or hand-written labels could prevent patients from understanding how to use their medical treatment. Dispensing by physicians can lead to abuse. In this respect, the following risk minimization measures can be cited: creating databases containing information related to the use and the return of medicinal products, using clear labels that specify proper disposal, adopting regulations for internet pharmacies and guidelines for patient counselling [1,2].

Patients are also responsible for environmental contamination with active pharmaceutical compounds. Self-medication, storing excessive stocks of medicinal products at home, excessive direct-to-consumer advertising, polytherapy, particularly in elderly patients, patient noncompliance to medication therapy and adverse effects are factors that can lead to the accumulation of unused or expired medicines and consequently to their improper disposal $[2,69,70,71]$. Patient education regarding the rational consumption of medicinal products and the correct disposal of unused or expired medicines should be imparted through information campaign and take-back programs, also named pharmaceutical-return programs $[2,7,69,72]$.

\section{Waste disposal management}

Diverse management strategies should be taken into consideration in order to minimize the environmental impact of pharmaceutical waste [15]. As mentioned above, pharmaceutical waste includes unused and expired medicinal products, as well as containers with pharmaceutical residues (blister packs, vials, bottles, bags), gloves and masks [3]. Waste can be classified as soft and sharp or as hazardous (infectious) and non-hazardous [73]. 
Cytotoxic medicines are considered to be hazardous and genotoxic pharmaceutical waste because of their highly mutagenic, teratogenic and carcinogenic properties [3].

All pharmaceutical waste should be collected in specific, color-coded containers before suitable waste treatment is applied $[3,74,75]$. Most of the times, pharmaceutical waste is disposed through incineration, a heat treatment technique which consists in combustion at high temperature $[3,69,75]$. Other waste treatment techniques include compact low temperature gasification (temperature of up to $550^{\circ} \mathrm{C}$ ), autoclave, chemical sterilization, radiofrequency irradiation, microwave, hot oil systems or alkaline hydrolysis. Some disposal techniques such as landfill, open burning or mechanical destruction have limited application due to their high risk of environmental pollution [73]. Active pharmaceutical ingredients can be found in wastewaters because of patients flushing down the toilet unused medicines. Human medicine use inevitably leads to excretion by urine and faeces thus increasing the levels of active pharmaceutical ingredients in wastewaters. Wastewaters are treated with common procedures (biological, physical and chemical) for removing contaminants, although most of the times, medicines cannot be efficiently eliminated $[3,76]$. As a result, different improvements should be made to wastewater treatment, such as ultrafiltration, reversed osmosis, ozonation and the use of activated carbon $[3,62,76]$.

\section{Towards a greener community pharmacy}

One of the activities that pharmacies can deploy for minimizing the environmental impact of medicinal products is collecting unused or expired medicinal products from patients. In the document called "Green Pharmacy Practice", FIP makes some recommendations to community pharmacies regarding pharmaceutical waste collection and disposal. If they wish, pharmacies can obtain accreditation for their waste management activity although this process is rather expensive. Even if pharmacies are not compelled to get an accreditation, they should elaborate standard operating procedures for the activity of collecting unused and expired medicines from patients, as well as for pharmaceutical waste disposal. Also, community pharmacies can conclude different types of agreements, as follows: with companies that collect pharmaceutical waste for proper disposal, with local authorities for a better management of collection programs and information campaigns, with manufacturers of medicinal products for correct waste collection and for helping pharmacists organize their waste management activity [3].

As far as the communication with patients is concerned, pharmacists are best equipped to provide information regarding medicinal products, including their environmental risk. Through counselling, pharmacist should also inform patients on the proper disposal of unused or expired medicines by encouraging them to return such medicines to a community pharmacy. Pharmacists should also inform patients about the proper packaging of medicines before returning them to the pharmacy. All information concerning the proper disposal of unused or expired medicines should also be provided in writing $[3,77,78]$.

Community pharmacies should be involved in collection programs, activity which represents an easy way of minimizing the presence of pharmaceuticals in the environment [79]. For example, in Switzerland, pharmacies collect $237 \mathrm{~g} / \mathrm{capita} /$ year of unused medicinal products, followed by countries such as France, Luxembourg, Ireland and Sweden. The European average of pharmaceutical waste collected from patients ranges between $10 \mathrm{~g}$ and $100 \mathrm{~g} / \mathrm{capita} /$ year. Most South Eastern countries collect lower amounts of unused or expired medicines than the European average [78]. In Romania, researchers conducted a study in order to establish whether Romanian patients return their unused or expired medicines to a community pharmacy. Less than $1 \%$ of the interviewed patients reported actually returning these medicines to a pharmacy, while the majority threw them away as garbage [69]. This poor collecting service can be explained by the geographical distribution of community pharmacies (patients should be able to return their unused or expired medicinal products to the nearest pharmacy), the lack of patient privacy when disposing pharmaceutical waste and the absence of specific containers in the pharmacy [78].

As far as the relation between pharmacists and other healthcare professionals is concerned, FIP encourages communication with physicians in order to properly evaluate and prescribe medicinal products that present a minimal risk of environmental contamination [3]. For example, in Sweden, the Drug Therapeutic Committee and the Health and Medical Care Administration of the Stockholm County Council created a website containing information related to medicinal products, where they are classified by using both their environmental hazard and risk. Environmental hazard of a medicinal product is characterized by persistence, bioaccumulation and toxicity (PBT). For each of these characteristics a numerical value of $0-3$ is established, taking into consideration the results of environmental hazard assessment. According to these criteria, the sum of these values for each medicinal product can range from 0 to 9, a high value of the PBT index meaning a high environmental impact. The environmental risk is based on the risk of aquatic system toxicity of any medicinal product, which can be insignificant, low, moderate or high [80]. These factors could be taken into account when prescribing and/or dispensing a medicinal product.

\section{Conclusions}

Pharmaceutical waste can be placed among other environmental contaminants, studies showing its presence in water and soil. Therefore, risk minimization actions should be taken by the pharmaceutical industry, physicians, pharmacists, other healthcare professionals 


\section{Pharmacy}

and the final consumer. The pharmaceutical industry could develop alternative eco-friendly methods for obtaining and manufacturing medicinal products. Physicians should adapt as much as possible any medicinal therapy to the needs of each patient without endangering the safety of both the patient and the environment. Pharmacists should inform patients about returning unused or expired medicinal products to community pharmacies. Also, an efficient pharmacist - patient relationship could increase public awareness regarding pharmaceutical waste and proper medicines disposal. Community pharmacies can organize collection programs for unused or expired medicines and should collaborate with different authorities and waste disposal companies in order to mitigate the environmental impact of medicinal products.

\section{References}

1. Daughton CG. Cradle-to-cradle stewardship of drugs for minimizing their environmental disposition while promoting human health. I. Rationale for and avenues toward a green pharmacy. Environ Health Perspect. 2003;111(5):754-774.

2. Daughton CG, Ruhoy IS. Green pharmacy and pharmEcovigilance: prescribing and the planet. Expert Rev Clin Pharmacol. 2011;4(2):211-232.

3. International Pharmaceutical Federation (FIP). Green pharmacy practice: Taking responsibility for the environmental impact of medicines 2015. Available from: https://fip.org/files/ fip/publications/2015-12-Green-Pharmacy-Practice.pdf.

4. Kreisberg J. Greener pharmacy proper medicine disposal protects the environment. Integrative Medicine. 2007;6(4):50-52. 5. KNAPPE. Knowledge and Need Assessment on Pharmaceutical Products in Environmental Waters, KNAPPE Final Report. 2008 Available from: https:/cordis.europa.eu/docs/ publications/1245/124584761-6_en.pdf.

6. Executive Agency for Health and Consumers. Study on the environmental risks of medicinal products, final report. . 2013 Available from: https://ec.europa.eu/health/sites/health/files/files/ environment/study_environment.pdf.

7. Kümmerer K. Sustainable from the very beginning: rational design of molecules by life cycle engineering as an important approach for green pharmacy and green chemistry. Green Chem. 2007;9:899-907.

8. Kümmerer K. Pharmaceuticals in the Environment. Annu Rev Environ Resour. 2010;35:57-75.

9. Baron M. Towards a Greener Pharmacy by More Eco Design. Waste Biomass Valor. 2012;3:395-407.

10. Daughton CG. Cradle-to-cradle stewardship of drugs for minimizing their environmental disposition while promoting human health. II. Drug disposal, waste reduction, and future directions. Environ Health Perspect. 2003;111(5):775-785.

11. Directive 2001/83/EC of the European Parliament and of the Council of 6 November 2001 on the community code relating to medicinal products for human use. Official Journal of the European Union, L 311/28.11.2001. Available from: https://eurlex.europa.eu/legal-content/EN/TXT/?qid=1527866260154\&uri $=$ CELEX:02001L0083-20121116.

12. Directive 2001/82/EC of the European Parliament and of the Council on the community code relating to veterinary medicinal products. Official Journal of the European Union, L
311/28.11.2001. Available from: https://eur-lex.europa.eu/legalcontent/EN/TXT/?qid=1527866863497\&uri=CELEX:0200 1L0082-20090807.

13. Amiard-Triquet C, Amiard JC, Mouneyrac C. Aquatic ecotoxicology. Advancing tools for dealing with emerging risks. 1st ed. Academic Press; 2015.

14. Heberer T. Occurrence, fate, and removal of pharmaceutical residues in the aquatic environment: a review of recent research data. Toxicol Lett. 2002;131:5-17.

15. Kummerer K. The presence of pharmaceuticals in the environment due to human use--present knowledge and future challenges. J Environ Manage. 2009;90:2354-2366.

16. Zhang Y, Geissen SU. Prediction of carbamazepine in sewage treatment plant effluents and its implications for control strategies of pharmaceutical aquatic contamination. Chemosphere. 2010;80:1345-1352.

17. Caracciolo AB, Grenni P, Falconi F, Caputo MC, Ancona V, Uricchio VF. Pharmaceutical waste disposal: assessment of its effects on bacterial communities in soil and groundwater. Chem Ecol. 2011;27:43-51.

18. Repice C, Dal Grande M, Maggi R, Pedrazzani R. Licit and illicit drugs in a wastewater treatment plant in Verona, Italy. Sci Total Environ. 2013;463-464:27-34.

19. Gamarra JS Jr, Godoi AF, de Vasconcelos EC, de Souza KM, de Oliviera CM. Environmental Risk Assessment (ERA) of diclofenac and ibuprofen: a public health perspective. Chemosphere. 2015;120:462-469.

20. Owens B. Pharmaceuticals in the environment: a growing problem. The Pharmaceutical Journal. 2015 . Available from: https:/www.pharmaceutical-journal.com/news-andanalysis/ features/pharmaceuticals-in-the-environment-a-growingproblem/20067898.article.

21. Brandt KK, Amézquita A, Backhaus T, Boxall A, Coors A, Heberer T, et al. Ecotoxicological assessment of antibiotics: A call for improved consideration of microorganisms. Environ Int. 2015;85:189-205.

22. Meffe R, de Bustamante I. Emerging organic contaminants in surface water and groundwater: a first overview of the situation in Italy. Sci Total Environ. 2014;481:280-295.

23. Bu Q, Wang B, Huang J, Deng S, Yu G. Pharmaceuticals and personal care products in the aquatic environment in China: a review. J Hazard Mater. 2013;262:189-211.

24. Oldenkamp R, Huijbregts MA, Hollander A, Ragas AM. Environmental impact assessment of pharmaceutical prescriptions: Does location matter? Chemosphere. 2014;115:88-94.

25. Eissen M, Backhaus D. Pharmaceuticals in the environment: an educational perspective. Environ Sci Pollut Res Int. 2011;18:1555-1566.

26. Brown KD, Kulis J, Thomson B, Chapman TH, Mawhinney DB. Occurrence of antibiotics in hospital, residential, and dairy effluent, municipal wastewater, and the Rio Grande in New Mexico. Sci Total Environ. 2006;366(2-3):772-783.

27. Agunbiade FO, Moodley B. Occurrence and distribution pattern of acidic pharmaceuticals in surface water, wastewater, and sediment of the Msunduzi River, Kwazulu-Natal, South Africa. Environ Toxicol Chem. 2016;35(1):36-46.

28. Al-Khazrajy OS, Boxall AB. Risk-based prioritization of pharmaceuticals in the natural environment in Iraq. Environ Sci Pollut Res Int. 2016;23(15):15712-15726.

29. Calisto V, Esteves VI. Psychiatric pharmaceuticals in the environment. Chemosphere. 2009;77:1257-1274. 
30. Chen Y, Yu G, Cao Q, Zhang H, Lin Q, Hong Y. Occurrence and environmental implications of pharmaceuticals in Chinese municipal sewage sludge. Chemosphere. 2013;93:1765-1772.

31. Chitescu CL, Kaklamanos G, Nicolau AI, Stolker AA. High sensitive multiresidue analysis of pharmaceuticals and antifungals in surface water using U-HPLC-Q Exactive Orbitrap HRMS. Application to the Danube river basin on the Romanian territory. Sci Total Environ. 2015;532:501-511.

32. Evans S, Bagnall J, Kasprzyk-Hordern B. Enantiomeric profiling of a chemically diverse mixture of chiral pharmaceuticals in urban water. Environ Pollut. 2017;230:368-377.

33. Fent K, Weston AA, Caminada D. Ecotoxicology of human pharmaceuticals. Aquat Toxicol. 2006;76:122-159.

34. Isidori M, Lavorgna M, Nardelli A, Parrella A, Previtera L, Rubino M. Ecotoxicity of naproxen and its phototransformation products. Sci Total Environ. 2005;348:93-101.

35. Kasprzyk-Hordern B, Dinsdale RM, Guwy AJ. Illicit drugs and pharmaceuticals in the environment--forensic applications of environmental data. Part 1: Estimation of the usage of drugs in local communities. Environ Pollut. 2009;157:1773-1777.

36. Kasprzyk-Hordern B, Dinsdale RM, Guwy AJ. Illicit drugs and pharmaceuticals in the environment--forensic applications of environmental data, Part 2: Pharmaceuticals as chemical markers of faecal water contamination. Environ Pollut. 2009;157:1778-1786. 37. Kosjek T, Heath E. Occurrence, fate and determination of cytostatic pharmaceuticals in the environment. Trends Anal Chem. 2011;30(7):1065-1087.

38. Lees K, Fitzsimons M, Snape J, Tappin A, Comber S. Pharmaceuticals in soils of lower income countries: Physicochemical fate and risks from wastewater irrigation. Environ Int. 2016;94:712-723.

39. Li WC. Occurrence, sources, and fate of pharmaceuticals in aquatic environment and soil. Environ Pollut. 2014;187:193-201. 40. Lissemore L, Hao C, Yang P, Sibley PK, Mabury S, Solomon KR. An exposure assessment for selected pharmaceuticals within a watershed in Southern Ontario. Chemosphere. 2006;64: 717-729.

41. Lolić A, Paíga P, Santos L, Ramos S, Correia M, Delerue-Matos C. Assessment of non-steroidal anti-inflammatory and analgesic pharmaceuticals in seawaters of North of Portugal: occurrence and environmental risk. Sci Total Environ. 2015;508:240-250.

42. Moldovan Z, Schmutzer G, Tusa F, Calin R, Alder AC. An overview of pharmaceuticals and personal care products contamination along the river Somes watershed, Romania. J Environ Monit. 2007;9:986-993.

43. Riva F, Zuccato E, Castiglioni S. Prioritization and analysis of pharmaceuticals for human use contaminating the aquatic ecosystem in Italy. J Pharm Biomed Anal. 2015;106:71-78.

44. Scott TM, Phillips PJ, Kolpin DW, Colella KM, Furlong ET, Foreman WT, et al. Pharmaceutical manufacturing facility discharges can substantially increase the pharmaceutical load to U.S. wastewaters. Sci Total Environ. 2018;636:69-79.

45. Shraim A, Diab A, Alsuhaimi A, Niazy E, Metwally M, Amad M, et al. Analysis of some pharmaceuticals in municipal wastewater of Almadinah Almunawarah. Arab J Chem. 2017;10:719-29.

46. Van De Steene JC, Stove CP, Lambert WE. A field study on 8 pharmaceuticals and 1 pesticide in Belgium: removal rates in waste water treatment plants and occurrence in surface water. Sci Total Environ. 2010;408:3448-3453.

47. Vazquez-Roig P, Andreu V, Blasco C, Picó Y. Risk assessment on the presence of pharmaceuticals in sediments, soils and waters of the Pego-Oliva Marshlands (Valencia, eastern Spain). Sci Total Environ. 2012;440:24-32.

48. Wen ZH, Chen L, Meng XZ, Duana YP, Zhang ZS, Zeng EY. Occurrence and human health risk of wastewater-derived pharmaceuticals in a drinking water source for Shanghai, East China. Sci Total Environ. 2014;490:987-993.

49. Zuccato E, Castiglioni S, Fanelli R. Identification of the pharmaceuticals for human use contaminating the Italian aquatic environment. J Hazard Mater. 2005;122:205-209.

50. Jones OA, Lester JN, Voulvoulis N. Pharmaceuticals: a threat to drinking water? Trends Biotechnol. 2005;23:163-167.

51. Burns EE, Carter LJ, Kolpin DW, Thomas-Oates J, Boxall ABA. Temporal and spatial variation in pharmaceutical concentrations in an urban river system. Water Res. 2018;137:72-85.

52. Puckowski A, Mioduszewska K, Łukaszewicz P, Borecka M, Caban M, Maszkowska J. et al. Bioaccumulation and analytics of pharmaceutical residues in the environment: A review. J Pharm Biomed Anal. 2016;127:232-255.

53. Rice J, Proctor K, Lopardo L, Evans S, Kasprzyk-Hordern B. Stereochemistry of ephedrine and its environmental significance: exposure and effects directed approach. J Hazard Mater. 2018;348:39-46.

54. Barra Caracciolo A, Topp E, Grenni P. Pharmaceuticals in the environment: biodegradation and effects on natural microbial communities. A Review. J Pharm Biomed Anal. 2015;106:25-36. 55. Kodešová R, Kočárek M, Klement A, Golovko O, Koba O, Fér $\mathrm{M}$, et al. An analysis of the dissipation of pharmaceuticals under thirteen different soil conditions. Sci Total Environ. 2016;544:369-381.

56. Alygizakis NA, Gago-Ferrero P, Borova VL, Pavlidou A, Hatzianestis I, Thomaidis NS. Occurrence and spatial distribution of 158 pharmaceuticals, drugs of abuse and related metabolites in offshore seawater. Sci Total Environ. 2016;541:1097-1105.

57. Brambilla G, Testa C. Food safety/food security aspects related to the environmental release of pharmaceuticals. Chemosphere. 2014;115:81-87.

58. He BS, Wang J, Liu J, Hu XM. Eco-pharmacovigilance of nonsteroidal anti-inflammatory drugs: necessity and opportunities. Chemosphere. 2017;181:179-189.

59. Carlier L, Baron M, Chamayou A, Couarraze G. Greener pharmacy using solvent-free synthesis: Investigation of the mechanism in the case of dibenzophenazine. Powder Technol. 2013;240:41-47.

60. Ott D, Kralisch D, Denčić I, Hessel V, Laribi Y, Perrichon PD, et al. Life cycle analysis within pharmaceutical process optimization and intensification: case study of active pharmaceutical ingredient production. ChemSusChem. 2014;(12):3521-3533.

61. Leder C, Rastogi T, Kümmerer K. Putting benign by design into practice-novel concepts for green and sustainable pharmacy: designing green drug derivatives by non-targeted synthesis and screening for biodegradability. Sustainable Chemistry and Pharmacy. 2015;2:31-36.

62. Lubick N. Opening the "green pharmacy". Environ Sci Technol. 2008;42(23):8620-8621.

63. Popa Ungureanu C, Favier L, Bahrim G, Amrane A. Response surface optimization of experimental conditions for carbamazepine biodegradation by Streptomyces MIUG 4.89. N Biotechnol. 2015;32(3):347-357.

64. Vatovec C, Van Wagoner E, Evans C. Investigating sources of pharmaceutical pollution: Survey of over-the-counter and prescription medication purchasing, use, and disposal practices 
among university students. J Environ Manage. 2017;198(Pt 1):348-352.

65. Crain SM, Shen KF. Acute thermal hyperalgesia elicited by low-dose morphine in normal mice is blocked by ultra-lowdose naltrexone, unmasking potent opioid analgesia. Brain Res. 2001;888(1):75-82.

66. Klatte S, Schaefer HC, Hempel M. Pharmaceuticals in the environment - a short review on options to minimize the exposure of humans, animals and ecosystems. Sustainable Chemistry and Pharmacy. 2017;5:61-66.

67. Straub JO. Reduction in the environmental exposure of pharmaceuticals through diagnostics, personalized healthcare and other approaches. A mini review and discussion paper. Sustainable Chemistry and Pharmacy. 2016;3:1-7.

68. Paulmichl M, Maliepaard M, Papaluca M, Grimstein C. Regulatory Considerations in Pharmacogenomics at EMA and US FDA. In: Bertino SJ, DeVane CL, Fuhr U, Kashuba AD, Ma JD, editors. Pharmacogenomics: An Introduction and Clinical Perspective. McGraw-Hill Education; 2013. p. 1-9. Available from: https://accesspharmacy.mhmedical.com/content.aspx?book $\mathrm{id}=511 \&$ sectionid $=40849371$.

69. Tit DM, Bungau S, Nistor Cseppento C, Copolovici DM, Buhas C. Disposal of unused medicines resulting from home treatment in Romania. J Environ Prot Ecol. 2016;17(4):14251433.

70. Thomas F. Pharmaceutical waste in the environment: a cultural perspective. Public health panorama. 2017;3(1):127-132.

71. Tong AY, Peake BM, Braund R. Disposal practices for unused medications around the world. Environ Int. 2011;37:292-298.

72. Glassmeyer ST, Hinchey EK, Boehme SE, Daughton CG,
Ruhoy IS, Conerly O, et al. Disposal practices for unwanted residential medications in the United States. Environ Int. 2009;35:566-572.

73. Blenkharn JI. Clinical waste management. In: Blenkharn JI, editor. Healthcare Wastes. London: Blenkharn Environmental; 2015. pp 2-25.

74. Stanton C. Exploring safer methods for managing pharmaceutical waste. AORN Connections. 2011;94(4):1-3.

75. Popescu DE, Bungau C, Prada M, Domuta C, Bungau S, Tit DM. Waste management strategy at a public University in smart city context. J Environ Prot Ecol. 2016;17(3):1011-1020.

76. Verlicchi P, Galletti A, Petrovic M, Barceló D, Al Aukidy M, Zambello E. Removal of selected pharmaceuticals from domestic wastewater in an activated sludge system followed by a horizontal subsurface flow bed - analysis of their respective contributions. Sci Total Environ. 2013;454-455:411-425.

77. Gray-Winnett MD, Davis CS, Yokley SG, Franks AS. From dispensing to disposal: the role of student pharmacists in medication disposal and the implementation of a take-back program. J Am Pharm Assoc (2003). 2010;50(5):613-618.

78. Jonjic' D, Vitale K. Issues around household pharmaceutical waste disposal through community pharmacies in Croatia. Int $\mathrm{J}$ Clin Pharm. 2014;36:556-563.

79. Barnett-Itzhaki Z, Berman T, Grotto I, Schwartzberg E. Household medical waste disposal policy in Israel. Isr J Health Policy Res. 2016 Oct 10;5:48.

80. Janusinfo. Stockholm: Environment and pharmaceuticals: Classification. Available from: http://www.janusinfo.se/ Beslutsstod/Environment-and-Pharmaceuticals/Dokument/ Classification/. 